\title{
Citation Classics in Patient Engagement Research: An Analysis of the 50 Most Cited Articles
}

\author{
Richard Huan Xu, Eliza Lai-Yi Wong* \\ JC School of Public Health and Primary Care, The Chinese University of Hong Kong, Hong Kong, China \\ Email: huanxu@link.cuhk.edu.hk, ^lywong@cuhk.edu.hk
}

How to cite this paper: Xu, R.H. and Wong, E.L.-Y. (2017) Citation Classics in Patient Engagement Research: An Analysis of the 50 Most Cited Articles. Open Journal of Nursing, 7, 630-644.

https://doi.org/10.4236/ojn.2017.76047

Received: April 12, 2017

Accepted: June 11, 2017

Published: June 14, 2017

Copyright $\odot 2017$ by authors and Scientific Research Publishing Inc. This work is licensed under the Creative Commons Attribution International License (CC BY 4.0).

http://creativecommons.org/licenses/by/4.0/ (c) (i) Open Access

\begin{abstract}
Background: Patient engagement offers a promising pathway toward improved population health, better-quality care, and greater cost efficiency. The objective of the current study is to identify and analyze the characteristics of the 50 most frequently cited articles in patient engagement journals. Methods: The ISI Journal Citation Reports: Science Edition 2014 database was used to determine the most frequently cited published articles in Dec 2016. The most cited 50 articles were selected and assessed according to the published journal, origin of institutions, publication year, impact factor, topic, and type of study. Results: The 50 selected articles were published in 19 journals, the majority of which originated from the UK. The most common study design was quantitative study and reviews. The improvement of health care services quality and the construction of engagement model were the top two topics. And 2013 is the most published year receiving the most citations. Conclusions: Our findings provide a historical perspective on the scientific progress of patient engagement and allow for recognition of important developments and limitations in this field.
\end{abstract}

\section{Keywords}

Citation Analysis, Patient Engagement, Publication, Systematic Evaluation

\section{Introduction}

Given the governments around the world struggling to meet the health needs of their citizens in the face of rising costs, aging populations, and massive variations in health care during the last 20 years [1], patient engagement as a powerful and potentially beneficial force has been strongly introduced into our daily health care services. However, how can we evaluate the progress and contribu- 
tions of this "blockbuster drug of the century" from a series of researches and studies [2]? Citation analysis is a commonly used bibliometric method, which could be used to explore the impact of the field, the impact of a number of researchers and the impact of some particular articles [3].

Citation classics for the most cited articles as a new research method were firstly introduce by Garfield in 1977 [4]. For now, a variety of journals and research fields have published their citation classics. It always offers a distinctive insight into the history and development of the research for the reader.

Meanwhile, it is also very useful to use citation classics to identify the authors who have published the significant findings on any particular topics, as well as the short or long term impact of their works from the literary perspective [5]. Extensively cited articles from patient service journals also serve as an important role to inspire the medical staffs, researchers, or policymakers to reflect and improve the current plans and policies.

Identification of citation classics has been conducted in various medical fields, but very few in the domain of patient care. According to our literature searching, until now, none of the previous citation studies had focused on the patient engagement. Therefore the aim of the present study is to identify and examine the characteristics of the 50 most frequently cited articles in patient engagement.

\section{Method}

In the light of no category is named "Patient Engagement" of ISI Journal Citation Report: Science Edition 2014 (Web of Knowledge), Twenty-five journals dedicated to patient related service and care and its subspecialties were selected from the Journal Citation Report 2014 under the subject category "Health Care Science and Services", "Health Policies and Services", "Nursing" and "Public, Environment \& Occupational Health". All searches were chosen peer-reviewed literature, confined to publish between January 1995 and December 2016, including e-publications ahead of print. The 50 most frequently cited articles in the journals dedicated to patient engagement were identified using the database of the ISI web of science (Web of Knowledge), with the Science Citation Index Expanded (1965-) and Social Sciences Citation Index (1956-). Only English article had been considered for reviewing.

As we know, there is not a unified and standard definition of patient engagement. In addition, a lot of other conceptions, like patient involvement, patient activations, or customer engagement under the umbrella of the patient-centered care, had some kinds of similarities and overlaps to each other. Therefore, in order to ensure our conclusions' consistency and accuracy, we only included the articles discussing the concept of patient engagement through two independent reviewers, but not include or discuss the other parallel concepts like, patient activation, patient adherence, patient involvement, patient participation or patient empowerment.

All articles were collected initially through the database of electronic copies. For those the electronic copies were unavailable, hardcopies were sought out 
through CUHK library from local or oversea sources as an alternative. Search results were stored in a Mendeley database (ver. 1.15.2, Elsevier, New York, NY) and duplicate records were removed. Two reviewers (RX and EW), together screened all the titles and abstracts to evaluate and decide which articles to be selected based on the inclusion and exclusion criteria. Using a data extraction form, all full text of eligible articles which were identified would be gone through and evaluated independently by two reviewers (RX and EW). All articles which neither met the inclusion criteria nor met the exclusion criteria were listed in a table independently by two reviewers and verified together. If there were any disagreements of article selection, the disputed articles would be retrieved and reviewed by two authors again, or appointed to a third researcher to evaluate it. The whole process of consistency and accuracy of article selection based on the pre-set criteria would not be completed until a consensus had been made among the authors. The selected articles were collected and analyzed according to various characteristics, including 1) year of publication; 2) journal name; 3) Impact factor of journal; 4) number of citation; 5) authorship; 6) number of publications per year; 7) institution; 8) country; and 9) study design.

The study design was further divided into the following categories: 1) prospective trials, including randomized controlled, non-randomized controlled, and uncontrolled experimental trials; 2) qualitative studies, including interview and focus group study; 3 ) surveys, including questionnaire and validation studies; 4) reviews, including literature reviews, systematic reviews and meta-analysis; and 5) other designs that do not belong to any of the above four categories.

\section{Results}

Of the 25 journals included in our bibliometric analysis, only 19 provided articles in our top 50 list (Table 1). The earliest journal, as we know, is the "Medical Care" from the US, which published its first volume in 1963. The youngest journal is the "BMC Implementation Science" from UK, which published its first volume in 2006. In general, the journals related to patient engagement are relatively new, among which the oldest one reported the results of patient engagement has only been published for about 50 years. The analysis of impact factor shows that the 5-year impact factor for all 19 journals ranged from 1.47 to 5.25. And all of them were published in English. According to the searching results from JCR: Science Edition 2014, during the whole study period from 1956 to 2016, there were totally 463 records found related to patient engagement. 244 of them had been cited at least once, which account for $52.8 \%$. The top article received 210 citations, and only three articles had been cited over 100 times in our fixed search categories.

Table 1 also indicated the breakdown of the 19 journals included in this study. Health Affairs (9 articles), [1] [6]-[13] Journal of Medical Internet Research (6 articles) [14]-[19] and BMC Health Service Research (6 articles) [20]-[25] had occupied the top three of the list, which covered nearly $40 \%$ of all the included articles. Besides, no correlation between number of citations and impact factor has been confirmed in our study. 
Table 1. Summary of included journals.

\begin{tabular}{|c|c|c|c|c|c|}
\hline No. & Title & Abbreviation & Volume 1 at & Impact factor & \# of top 50 cited articles \\
\hline 1 & Health Affairs & HEALTH AFFAIR & 1981 & 4.96 & 9 \\
\hline 2 & Journal of Medical Internet Research & J MED INTERNET RES & 1999 & 5.25 & 6 \\
\hline 3 & BMC Health Service Research & BMC HEALTH SERV RES & 2001 & 1.71 & 6 \\
\hline 4 & Patient Education and Counseling & PATIENT EDUC COUNS & 1983 & 2.89 & 5 \\
\hline 5 & Journal of Advanced Nursing & J ADV NURS & 1976 & 1.91 & 4 \\
\hline 6 & Health Expectations & HEALTH EXPECT & 1998 & 3.75 & 3 \\
\hline 7 & AIDS Patient Care and STDs & AIDS PATIENT CARE ST & 1987 & 3.49 & 3 \\
\hline 8 & BMJ Quality \& Safety (Quality \& safety in Health Care) & BMJ QUAL SAF & 1992 & 4.99 & 2 \\
\hline 9 & Medical Care & MED CARE & 1963 & 3.48 & 2 \\
\hline 10 & BMC Family Practice & BMC FAM PRACT & 2000 & 1.67 & 1 \\
\hline 11 & BMC Implementation Science & IMPLEMENT SCI & 2006 & 4.10 & 1 \\
\hline 12 & International Journal of Nursing Studies & INT J NURS STUD & 1964 & 3.64 & 1 \\
\hline 13 & Social Science \& Medicine & SOC SCI MED & 1982 & 3.59 & 1 \\
\hline 14 & Quality of Life Research & QUAL LIFE RES & 1992 & 3.08 & 1 \\
\hline 15 & Journal of Patient Safety & J PATIENT SAF & 2005 & 2.44 & 1 \\
\hline 16 & Nursing Outlook & NURS OUTLOOK & 1994 & 2.43 & 1 \\
\hline 17 & Health & HEALTH & 1997 & 1.96 & 1 \\
\hline 18 & Health Communication & HEALTH COMMUN & 1989 & 1.93 & 1 \\
\hline 19 & Journal of Nursing Administration & J NURS ADMIN & 1971 & 1.47 & 1 \\
\hline
\end{tabular}

Table 2 summarized the 50 top-cited articles related to patient engagement in descending order, according to the cited numbers by each article [1] [6]-[54]. The most frequently cited article "The impact of nursing work environments on patient safety outcomes - The mediating role of burnout/engagement" received 198 citations [41]. Furthermore, 44 articles were originated from universities [1] [7] [8] [10] [12] [14]-[30] [32] [33] [34] [36]-[54]. Six of them were accomplished by research institutes [6] [9] [11] [13] [31] [35]. The total cited frequency is 1387 .

Type of article was most frequently survey design with 25 contributions [1] [6] [8] [9] [12] [15] [20] [21] [26] [28] [29] [30] [31] [32] [34] [39] [40] [41] [42] [43] [45] [47] [48] [49] [52]; 10 were systematic review or meta-analysis [10] [16] [22] [23] [27] [33] [36] [37] [46] [51]; 7 were trial design [14] [17] [18] [19] [24] [35] [54]; 2 were qualitative studies [25] [50]; and the other six articles deal with other designs [7] [11] [13] [38] [44] [53] (Table 3).

Our study also showed that the US dominates the list of the 50 most cited articles with nearly $60 \%$ of contributions (Table 4) [6]-[13] [16] [17] [18] [19] [22] [24] [27] [29] [30] [31] [32] [35] [36] [37] [38] [39] [42] [43] [44] [45] [49] [51]. UK was the second one, possessing 11 articles (22\%) [1] [14] [21] [25] [28] [33] [34] [41] [46] [52] [53], followed by Australia [20] [40] [47] [54] and Canada, Finland, New Zealand, Netherlands, and Israel contributed to the rest five articles [15] [23] [26] [48] [50]. 
Table 2. Description of top 50 cited articles in descending order according to the number of citations each received.

\begin{tabular}{|c|c|c|c|c|}
\hline No. & Author (Year) (Country) & Title & Cited & Organization \\
\hline 1 & Laschinger, et al. (2006) (UK) & $\begin{array}{l}\text { The impact of nursing work environments on patient safety outcomes-The } \\
\text { mediating role of burnout/engagement }\end{array}$ & 210 & University \\
\hline 2 & Davis, et al. (2007) (UK) & $\begin{array}{c}\text { Patient involvement in patient safety: what factors influence patient participation and } \\
\text { engagement? }\end{array}$ & 113 & Research Org. \\
\hline 3 & Carman, et al. (2013) (US) & $\begin{array}{c}\text { Patient And Family Engagement: A Framework For Understanding The Elements } \\
\text { And Developing Interventions And Policies }\end{array}$ & 113 & Research Org. \\
\hline 4 & Franklin, et al. (2008) (UK) & $\begin{array}{c}\text { Patients” Engagement With “Sweet Talk”-A Text Messaging Support System for } \\
\text { Young People With Diabetes }\end{array}$ & 68 & University \\
\hline 5 & Gruman, et al. (2010) (US) & $\begin{array}{c}\text { From patient education to patient engagement: Implications for the field of patient } \\
\text { education }\end{array}$ & 59 & Research Org. \\
\hline 6 & Ruusuvuori (2001) (FIN) & $\begin{array}{l}\text { Looking means listening: coordinating displays of engagement in doctor-patient } \\
\text { interaction }\end{array}$ & 54 & University \\
\hline 7 & Koh, et al. (2013) (US) & $\begin{array}{c}\text { A Proposed "Health Literate Care Model" Would Constitute A Systems Approach To } \\
\text { Improving Patients' Engagement In Care }\end{array}$ & 43 & Research Org. \\
\hline 8 & Furukawa, et al. (2014) (US) & $\begin{array}{c}\text { Despite Substantial Progress In EHR Adoption, Health Information Exchange And } \\
\text { Patient Engagement Remain Low In Office Settings }\end{array}$ & 42 & Research Org. \\
\hline 9 & Domecq, et al. (2014) (US) & Patient engagement in research: a systematic review & 40 & Research Org. \\
\hline 10 & Cabral, et al. (2007) (US) & $\begin{array}{l}\text { Outreach program contacts: Do they increase the likelihood of engagement and } \\
\text { retention in HIV primary care for hard-to-reach patients? }\end{array}$ & 34 & University \\
\hline 11 & Staniszewska, et al. (2004) (UK) & $\begin{array}{c}\text { Patients' evaluations of the quality of care: influencing factors and the importance of } \\
\text { engagement }\end{array}$ & 33 & Research Org. \\
\hline 12 & Couper, et al. (2010) (US) & $\begin{array}{c}\text { Engagement and Retention: Measuring Breadth and Depth of Participant Use of an } \\
\text { Online Intervention }\end{array}$ & 33 & University \\
\hline 13 & Broom, et al. (2008) (UK) & $\begin{array}{c}\text { The role of the internet in cancer patients' engagement with complementary and } \\
\text { alternative treatments }\end{array}$ & 33 & University \\
\hline 14 & Martinez, et al. (2009) (US) & $\begin{array}{l}\text { Patient-clinician information engagement increases treatment decision satisfaction } \\
\text { among cancer patients through feeling of being informed }\end{array}$ & 27 & University \\
\hline 15 & Irizarry, et al. (2015) (US) & Patient Portals and Patient Engagement: A State of the Science Review & 25 & University \\
\hline 16 & Thomson, et al. (2005) (UK) & $\begin{array}{l}\text { Tensions in public health policy: patient engagement, evidence-based public health } \\
\text { and health inequalities }\end{array}$ & 24 & University \\
\hline 17 & Kralik, et al. (1997) (AU) & Engagement and detachment: Understanding patients' experiences with nursing & 23 & Research Org \\
\hline 18 & Knowlton, et al. (2010) (US) & $\begin{array}{c}\text { Antiretroviral Use Among Active Injection-Drug Users: The Role of Patient-Provider } \\
\text { Engagement and Structural Factors }\end{array}$ & 23 & University \\
\hline 19 & Cosgrove, et al. (2013) (US) & $\begin{array}{c}\text { Ten Strategies To Lower Costs, Improve Quality, And Engage Patients: The View } \\
\text { From Leading Health System CEOs }\end{array}$ & 22 & Research Org. \\
\hline 20 & Tripathi, et al. (2009) (US) & Engaging Patients For Health Information Exchange & 22 & Research Org. \\
\hline 21 & Lewis, et al. (2009) (US) & $\begin{array}{l}\text { Examining Cross-Source Engagement With Cancer-Related Information and Its } \\
\text { Impact on Doctor-Patient Relations }\end{array}$ & 21 & University \\
\hline 22 & Young, et al. (2007) (AUS) & $\begin{array}{l}\text { Patient Engagement and Coaching for Health: The PEACH study a cluster } \\
\text { randomised controlled trial using the telephone to coach people with type } 2 \text { diabetes } \\
\text { to engage with their GPs to improve diabetes care: a study protocol }\end{array}$ & 21 & University \\
\hline 23 & Piette, et al. (2013) (US) & $\begin{array}{c}\text { Engagement With Automated Patient Monitoring and Self-Management Support } \\
\text { Calls Experience With a Thousand Chronically III Patients }\end{array}$ & 21 & University \\
\hline 24 & Protheroe, et al. (2008) (UK) & $\begin{array}{l}\text { Promoting patient engagement with self-management support information: } \\
\text { a qualitative meta-synthesis of processes influencing uptake }\end{array}$ & 20 & University \\
\hline 25 & Mirzaei, et al. (2013) (AUS) & $\begin{array}{l}\text { A patient-centred approach to health service delivery: improving health outcomes for } \\
\text { people with chronic illness }\end{array}$ & 19 & University \\
\hline 26 & Christopoulos, et al. (2013) (US) & $\begin{array}{c}\text { "Taking a Half Day at a Time": Patient Perspectives and the HIV Engagement in } \\
\text { Care Continuum }\end{array}$ & 18 & Research Org. \\
\hline
\end{tabular}




\section{Continued}

27 Cornelia, et al. (2011) (NLD)

28 Abdelhadi, et al. (2011) (ISR)

Han, et al. (2013) (US)

Forbat, et al. (2009) (UK)

Grande, et al. (2014) (US)

Berger, et al. (2013) (US)

Pelletier, et al. (2013) (US)

Schaefer, et al. (2005) (US)

Sadasivam, et al. (2011) (US)

Cox, et al. (2012) (US)

Laurance, et al. (2014) (UK)

Frank, et al. (2015) (US)

Coventry. et al. (2014) (UK)

Tancredi, et al. (2013) (US)

Pryor, et al. (2010) (AUS)

Shippee, et al. (2013) (US)

Christopher, et al. (2015) (US)

Burns, et al. (2014) (CAN)

Sandy, et al. (2013) (US)

Danis, et al. (2012) (US)

Sheridan, et al. (2012) (NZL)

8 Holzmueller, et al. (2012) (US)

9 Ingersoll \& Berger (2015) (US)

Oostendorp, et al. (2015) (UK)
Determinants of Engagement in Face-to-Face and Online Patient Support Groups

University

Promoting patient care: work engagement as a mediator between ward service climate and patient-centred care

Survey Shows That Fewer Than A Third Of Patient-Centered Medical Home Practices Engage Patients In Quality Improvement

Engaging patients in health care: An empirical study of the role of engagement on attitudes and action

A classification model of patient engagement methods and assessment of their feasibility in real-world settings

Promoting engagement by patients and families to reduce adverse events in acute care settings: a systematic review

Action brief: Patient engagement and activation: A health reform imperative and improvement opportunity for nursing

Continuity of care practices and substance use disorder patients' engagement in continuing care

Development of an Interactive, Web-Delivered System to Increase Provider-Patient Engagement in Smoking Cessation

Influence of race and socioeconomic status on engagement in pediatric primary care

Patient Engagement: Four Case Studies That Highlight The Potential For Improved Health Outcomes And Reduced Costs

16 University

16 University

15 University

15 University

13 University

12 University

11 University

10 University

10 University

10 University

Conceptual and practical foundations of patient engagement in research at the patient-centered outcomes research institute

$9 \quad$ Academy

Capacity, responsibility, and motivation: a critical qualitative evaluation of patient and practitioner views about barriers to self-management in people with multimorbidity

Targeted versus tailored multimedia patient engagement to enhance depression recognition and treatment in primary care: randomized controlled trial protocol for the AMEP2 study

Enhancing inpatient rehabilitation through the engagement of patients and nurses

Patient and service user engagement in research: a systematic review and synthesized framework

Patterns and predictors of patient and caregiver engagement in heart failure care: A multi-level dyadic study

"Practical" resources to support patient and family engagement in healthcare decisions: a scoping review

9 University 8 University

8 University

8 University

7 University

7 University

United Healthcare Experience Illustrates How Payers Can Enable Patient Engagement 6 Research Org.

Providers, Payers, The Community, And Patients Are All Obliged To Get Patient Activation And Engagement Ethically Right

5 Research Org.

Patients' engagement in primary care: powerlessness and compounding jeopardy. A qualitative study

A Framework for Encouraging Patient Engagement in Medical Decision Making

Parent Engagement With a Tele health-Based Parent-Mediated Intervention Program Outcomes

Measuring organisational readiness for patient engagement (MORE): an international online Delphi consensus study

The "deliberation and intervention of improving service quality" (17 articles) [8] [9] [11] [12] [14] [18] [20] [24] [28] [29] [35] [43] [45] [47] [49] [52] [54] is the main topic covered by these highly cited articles. Considerable focuses were 
also given to the topics of "development of model and framework" (15 articles) [1] [7] [10] [16] [17] [25] [30] [32] [36] [38] [44] [46] [51] [53] [55]. Followed by "professional-patient communication" (11 articles) [6] [15] [23] [26] [31] [34] [39] [40] [42] [48] [50], "patient safety" (3 articles) [27] [33] [41], and "scale development" (2 articles) [19] [21]. Other topics include "patient education" [37] and "the barriers to effective engagement" [22] (Table 5).

As shown in Table 6, articles were published from 1997 to 2015. The most published year is 2013 ( 12 articles). Nearly $70 \%$ of articles cited by top 50 were published after 2010 (34 articles). Compared to other years, 2013 is also the year that publications were most frequently cited (299 times).

\section{Discussion}

It is well recognized that a closer look at the number of citations could be very helpful to confirm the impact of the journals and the contributions by individual

Table 3. Study types of origin of the 50 most cited articles.

\begin{tabular}{cc}
\hline Type of articles & No. of articles \\
\hline Survey study & 25 \\
Systematic or meta-analysis & 10 \\
Trial design & 7 \\
Qualitative study & 2 \\
Others & 6 \\
\hline
\end{tabular}

Table 4. Countries of origin of the 50 most cited articles.

\begin{tabular}{cc}
\hline Country & No. of articles \\
\hline The United Kingdom & 11 \\
The United States & 30 \\
Canada & 1 \\
Netherland & 1 \\
Australia & 4 \\
Finland & 1 \\
Israel & 1 \\
New Zealand & 1 \\
\hline
\end{tabular}

Table 5. Main topics covered in the 50 most cited articles.

\begin{tabular}{cc}
\hline Domain & No. of articles \\
\hline The improvement of service quality & 17 \\
Model and framework development & 15 \\
Professional-patient communication & 11 \\
Patient safety & 3 \\
Scale development & 2 \\
Patient education & 1 \\
Barriers to effective engagement & 1 \\
\hline
\end{tabular}


Table 6. Years of origin of the 50 most cited articles.

\begin{tabular}{cc}
\hline Domain & No. of articles \\
\hline 1997 & 1 \\
2001 & 1 \\
2004 & 1 \\
2005 & 2 \\
2006 & 1 \\
2007 & 3 \\
2008 & 3 \\
2009 & 4 \\
2010 & 4 \\
2011 & 3 \\
2012 & 4 \\
2013 & 12 \\
2014 & 6 \\
2015 & 5 \\
\hline
\end{tabular}

authors [56]. Our work is the first one to evaluate the 50 top-cited articles in the literature of patient engagement, though this very important and valuable conception has been introduced into the area of health care service for nearly 20 years.

Firstly, we found all the 50 most cited articles were published by the authors or institutes from western countries. Amongst them, 62\% from North America (CAN 2 articles \& US 29 articles), 30\% from Europe. These figures indicated that there is a big gap, as well as opportunities, in studying patient engagement in Asia. Especially, countries and areas like Japan, China, and Hong Kong have being facing greater challenges of aging population than ever, which require them to transform its traditional provider-centered health care pattern to a modern patient-centered health care pattern as soon as possible.

Secondly, the range of cited articles related to patient engagement from top 50 articles is from 2 to 198, which is considerably lower than other areas related to health care services. For example, the range for citation of patient safety is 100 to 584 , and patient satisfaction, the range is 156 - 875 . It may be explained by two reasons. The first one is that the conception of "patient engagement" is relatively new. Although it has been existed for nearly 20 years, according to our study, the real peak of studying this topic started from 2010. The second reason is that, as we know, there are some partially similar and potentially overlapped conceptions had existed, for example, patient involvement, patient activation or customer engagement, which had attracted some scholars' attentions and published their research findings use other titles already. Therefore, it may be hard to identify all the articles or articles using the keyword as patient engagement.

Other observations are not surprising. Trends in the number of publications of patient engagement have been promising in recent 20 years. It reveals that 
more resources and attentions from governments and research institutes have been transferred to this more effective and efficient patient-centered health care pattern. This is consistent with the results of other previous studies that awareness of involving the patient in their own health care in order to promote the health outcomes was increasing for both professionals and patients [57]. And this condition may encourage and inspire more researchers to focus on the study of patient engagement in the future.

Another finding is the impact factor of the journals in patient engagement is not high. The journal with the highest impact factor, 5.25, is the "Journal of Medical Internet Research (JMIR)". However, there is an obvious limitation of the articles published in JMIR, that is most of them are assessing the patient engagement only based on the internet-related studies. By contrast, the topics are more pluralistic of the second top journal "Health Affairs" (The IF is 4.96). We hope more mainstream journals with higher impact factor could share more attentions on the topics of patient engagement.

Finally, the list of the top-cited articles identifies topics that reflect major tendency and development in patient engagement over the last 20 years. Nearly $70 \%$ of articles focused on the improvement of health care service quality and the construction of patient engagement model. These results indicate that the studies of patient engagement are still at an early and exploratory stage. Likewise, the main purpose of such kind of studies is establishing the relationship between patient engagement interventions and high quality of health care services. In terms of study types, the majority of the studies followed the quasi-experimental design, using interviews or surveys to evaluate the efficiency of interventions, among which only six studies employed the randomized design. This finding demonstrates that the quality of interventions in this area is still under-developed, and could benefit from further, stricter analysis.

Our study provides important information into how knowledge in the field of patient engagement has been introduced and developed in the last few decades. The current study shows the impressive advances in this field. Patient engagement is growing in studying patients' experience, health utility use and service efficiency. Our findings encourage that in the field of patient engagement, future influential studies and articles could be conducted and published, and further explore the role of patient play in the patient-centered care.

There are some limitations of our study. Firstly, we did not count the number of citations from articles published in books, which may lead to the missing of some very important articles during the review. The second one is that we only checked the articles written in English, which may lead to the selection bias that some good articles written in other languages being omitted. Thirdly, since there is not a recognized category called patient engagement through the search, we chose other four most related categories as our target source of journals, hence, some articles related to this area in other clinical, medical or social science categories might not be included. The last limitation is that patient engagement is a relatively new conception, which means the older articles are more likely to be 
cited than the newer ones, simply due to their longer existence. This means some more solid, rigorous, or even seminal works could not be listed in our search.

\section{Conclusion}

Although limitations exist, the review of the 50 top cited articles in patient engagement may be worthwhile on a few accounts. The data we provided imply how much knowledge and how many developments in the field of patient engagement have been disseminated and made during the last 20 years. Most studies reported the positive relationship between patient engagement and health outcomes makes us optimistic and convincible that the input of resources and capacities to make meaningful progress on this new field is worthwhile. These findings encourage more excellent researchers and influential journals to participate in the exploration of the role in patient engagement to improve health outcomes.

\section{Authors' Contributions}

RX conducted the literature review, statistical analysis and prepared the manuscript. EW conceived the study and gave careful advice and revised the manuscript. Both authors read and approved the final manuscript.

\section{References}

[1] Laurance, J., Henderson, S., Howitt, P.J., Matar, M., Al Kuwari, H., Edgman-Levitan, S., et al. (2014) Patient Engagement: Four Case Studies That Highlight the Potential for Improved Health Out-Comes and Reduced Costs. Health Affairs, 33, 1627-1634. http://content.healthaffairs.org/cgi/doi/10.1377/hlthaff.2014.0375

[2] Dentzer, S. (2013) Rx for the "Blockbuster Drug" of Patient Engagement. Health Affairs, 32, 202. https://doi.org/10.1377/hlthaff.2013.0037

[3] Pilkington, A. and Meredith, J. (2009) The Evolution of the Intellectual Structure of Operations Management-1980-2006: A Citation/Co-Citation Analysis. Journal of Operations Management, 27, 185-202. https://doi.org/10.1016/j.jom.2008.08.001

[4] Garfield, E. (1977) Introducing Citation Classics: The Human Side of Scientific Reports. Essays of an Information Scientist, 3, 1-2.

[5] Smith, D. (2007) Ten Citation Classics from the New Zealand Medical Journal. New Zealand Medical Journal, 120, 2871-2875.

[6] Danis, M. and Solomon, M. (2013) Providers, Payers, the Community, and Patients Are All Obliged to Get Patient Activation and Engagement Ethically Right. Health Affairs, 32, 401-407. http://content.healthaffairs.org/cgi/doi/10.1377/hlthaff.2012.1081

[7] Carman, K.L., Dardess, P., Maurer, M., Sofaer, S., Adams, K., Bechtel, C., et al. (2013) Patient and Family Engagement: A Framework for Understanding the Elements and Developing Interventions and Policies. Health Affairs, 32, 223-231. https://doi.org/10.1377/hlthaff.2012.1133

[8] Han, E., Scholle, S.H., Morton, S., Bechtel, C. and Kessler, R. (2013) Survey Shows That Fewer than a Third of Patient-Centered Medical Home Practices Engage Patients in Quality Improvement. Health Affairs, 32, 368-375.

https://doi.org/10.1377/hlthaff.2012.1183 
[9] Tripathi, M., Delano, D., Lund, B. and Rudolph, L. (2009) Engaging Patients for Health Information Exchange. Health Affairs, 28, 435-443. https://doi.org/10.1377/hlthaff.28.2.435

[10] Koh, H.K., Brach, C., Harris, L.M. and Parchman, M.L. (2013) A Proposed "Health Literate Care Model” Would Constitute a Systems Approach to Improving Patient's Engagement in Care. Health Affairs, 32, 357-367. https://doi.org/10.1377/hlthaff.2012.1205

[11] Sandy, L.G., Tuckson, R.V. and Stevens, S.L. (2013) United Healthcare Experience Illustrates How Payers Can Enable Patient Engagement. Health Affairs, 8, 14401445. https://doi.org/10.1377/hlthaff.2012.1082

[12] Furukawa, M.F., King J., Patel, V., Hsiao, C.J., Adler-Milstein, J. and Jha, A.K. (2014) Despite Substantial Progress in EHR Adoption, Health Information Exchange and Patient Engagement Remain Low in Office Settings. Health Affairs, 33, 1672-1679. https://doi.org/10.1377/hlthaff.2014.0445

[13] Cosgrove, D.M., Fisher, M., Gabow, P., Gottlieb, G., Halvorson, G.C., James, B.C., et al. (2013) Ten Strategies to Lower Costs, Improve Quality, and Engage Patients: The View from Leading Health System CEOs. Health Affairs, 32, 321-327. https://doi.org/10.1377/hlthaff.2012.1074

[14] Franklin, V.L., Greene, A., Waller, A., Greene, S.A. and Pagliari, C. (2008) Patients' Engagement with "Sweet Talk"-A Text Messaging Support System for Young People with Diabetes. Journal of Medical Internet Research, 10, e20.

http://www.jmir.org/2008/2/e20/ https://doi.org/10.2196/jmir.962

[15] Van Uden-Kraan, C.F., Drossaert, C.H.C., Taal, E., Smit, W.M., Bernelot Moens, H.J. and Van de Laar, M.A.F.J. (2011) Determinants of Engagement in Face-to-Face and Online Patient Support Groups. Journal of Medical Internet Research, 13, e106.

[16] Irizarry, T., De Vito Dabbs, A. and Curran, C.R. (2015) Patient Portals and Patient Engagement: A State of the Science Review. Journal of Medical Internet Research, 17, e148. https://doi.org/10.2196/jmir.4255

http://www.pubmedcentral.nih.gov/articlerender.fcgi?artid=4526960\&tool=pmcent $\underline{\text { rez\&rendertype }=\text { abstract }}$

[17] Sadasivam, R.S., Delaughter, K., Crenshaw, K., Sobko, H.J., Williams, J.H., Coley, H.L., et al. (2011) Development of an Interactive, Web-Delivered System to Increase Provider-Patient Engagement in Smoking Cessation. Journal of Medical Internet Research, 13, e87. https://doi.org/10.2196/jmir.1721

[18] Ingersoll, B. and Berger, N.I. (2015) Parent Engagement with a Telehealth-Based Parent-Mediated Inter-Vention Program for Children with Autism Spectrum Disorders: Predictors of Program Use and Parent Outcomes. Journal of Medical Internet Research, 17, e227. https://doi.org/10.2196/jmir.4913

[19] Couper, M.P., Alexander, G.L., Zhang, N., Little, R.J.A., Maddy, N., Nowak, M.A., et al. (2010) Engagement and Retention: Measuring Breadth and Depth of Participant Use of an Online Intervention. Journal of Medical Internet Research, 12, e52. https://doi.org/10.2196/jmir.1430

[20] Mirzaei, M., Aspin, C., Essue, B., Jeon, Y.-H., Dugdale, P., Usherwood, T., et al. (2013) A Patient-Centred Approach to Health Service Delivery: Improving Health Outcomes for People with Chronic Illness. BMC Health Services Research, 13, 251. http://www.biomedcentral.com/1472-6963/13/251 https://doi.org/10.1186/1472-6963-13-251

[21] Oostendorp, L.J., Durand, M.-A., Lloyd, A. and Elwyn, G. (2015) Measuring Organisational Readiness for Patient Engagement (MORE): An International Online 
Delphi Consensus Study. BMC Health Services Research, 15, 61.

http://www.biomedcentral.com/1472-6963/15/61

https://doi.org/10.1186/s12913-015-0717-3

[22] Domecq, J.P., Prutsky, G., Elraiyah, T., Wang, Z., Nabhan, M., Shippee, N., et al. (2014) Patient Engagement in Research: A Systematic Review. BMC Health Services Research, 14, 89. https://doi.org/10.1186/1472-6963-14-89

[23] Burns, K.K., Bellows, M., Eigenseher, C. and Gallivan, J. (2014) "Practical” Resources to Support Patient and Family Engagement in Healthcare Decisions: A Scoping Review. BMC Health Services Research, 14, 175.

http://www.ncbi.nlm.nih.gov/pubmed/24735787 https://doi.org/10.1186/1472-6963-14-175

[24] Tancredi, D.J., Slee, C.K., Jerant, A., Franks, P., Nettiksimmons, J., Cipri, C., et al. (2013) Targeted Versus Tailored Multimedia Patient Engagement to Enhance Depression Recognition and Treatment in Primary Care: Randomized Controlled Trial Protocol for the AMEP2 Study. BMC Health Services Research, 13, 141.

http://www.pubmedcentral.nih.gov/articlerender.fcgi?artid=3637592\&tool=pmcent rez\&rendertype $=$ abstract https://doi.org/10.1186/1472-6963-13-141

[25] Coventry, P.A., Fisher, L., Kenning, C., Bee, P. and Bower, P. (2014) Capacity, Responsibility, and Motivation: A Critical Qualitative Evaluation of Patient and Practitioner Views about Barriers to Self-Management in People with Multimorbidity. BMC Health Services Research, 14, 536.

http://www.biomedcentral.com/1472-6963/14/536 https://doi.org/10.1186/s12913-014-0536-y

[26] Abdelhadi, N. and Drach-Zahavy, A. (2012) Promoting Patient Care: Work Engagement as a Mediator between Ward Service Climate and Patient-Centred Care. Journal of Advanced Nursing, 68, 1276-1287.

https://doi.org/10.1111/j.1365-2648.2011.05834.x

[27] Berger, Z., Flickinger, T.E., Pfoh, E., Martinez, K. and Dy, S.M. (2014) Promoting Engagement by Patients and Families to Reduce Adverse Events in Acute Care Settings: A Systematic Review. BMJ Quality \& Safety, 23, 548-555.

http://www.ncbi.nlm.nih.gov/pubmed/24336575 https://doi.org/10.1136/bmjqs-2012-001769

[28] Broom, A. and Tovey, P. (2008) The Role of the Internet in Cancer Patients' Engagement with Complementary and Alternative Treatments. Health (London), 12, 139-155. https://doi.org/10.1177/1363459307086841

[29] Cabral, H.J., Tobias, C., Rajabiun, S., Sohler, N., Cunningham, C., Wong, M., et al. (2007) Outreach Program Contacts: Do They Increase the Likelihood of Engagement and Retention in HIV Primary Care for Hard-to-Reach Patients? AIDS Patient Care and STDs, 21, S-59-S-67.

http://www.liebertonline.com/doi/abs/10.1089/apc.2007.9986 https://doi.org/10.1089/apc.2007.9986

[30] Christopher, L.S., Vellone, E., Lyons, K.S., Cocchieri, A., Bidwell, J.T., D’Agostino, F., et al. (2015) Patterns and Predictors of Patient and Caregiver Engagement in Heart Failure Care: A Multi-Level Dyadic Study. International Journal of Nursing Studies, 52, 588-597. https://doi.org/10.1016/j.ijnurstu.2014.11.005

[31] Christopoulos, K.A., Massey, A.D., Lopez, A.M., Geng, E.H., Johnson, M.O., Pilcher, C.D., et al. (2013) "Taking a Half Day at a Time": Patient Perspectives and the HIV Engagement in Care Continuum. AIDS Patient Care and STDs, 27, 223-230. http://online.liebertpub.com/doi/abs/10.1089/apc.2012.0418 
[32] Cox, E.D., Nackers, K.A., Young, H.N., Moreno, M.A., Levy, J.F. and MangioneSmith, R.M. (2012) Influence of Race and Socioeconomic Status on Engagement in Pediatric Primary Care. Patient Education and Counseling, 87, 319-326. https://doi.org/10.1016/j.pec.2011.09.012

[33] Davis, R.E., Jacklin, R., Sevdalis, N. and Vincent, C.A. (2007) Patient Involvement in Patient Safety: What Factors Influence Patient Participation and Engagement? Health Expectations, 10, 259-267.

http://www.ncbi.nlm.nih.gov/pubmed/17678514 https://doi.org/10.1111/j.1369-7625.2007.00450.x

[34] Forbat, L., Cayless, S., Knighting, K., Cornwell, J. and Kearney, N. (2009) Engaging Patients in Health Care: An Empirical Study of the Role of Engagement on Attitudes and Action. Patient Education and Counseling, 74, 84-90.

http://linkinghub.elsevier.com/retrieve/pii/S0738399108004023 https://doi.org/10.1016/j.pec.2008.07.055

[35] Frank, L., Forsythe, L., Ellis, L., Schrandt, S., Sheridan, S., Gerson, J., et al. (2015) Conceptual and Practical Foundations of Patient Engagement in Research at the $\mathrm{Pa}$ tient-Centered Outcomes Research Institute. Quality of Life Research, 24, 1033 1041. https://doi.org/10.1007/s11136-014-0893-3

[36] Grande, S.W., Faber, M.J., Durand, M.A., Thompson, R. and Elwyn, G. (2014) A Classification Model of Patient Engagement Methods and Assessment of Their Feasibility in Real-World Settings. Patient Education and Counseling, 95, 281-287. https://doi.org/10.1016/j.pec.2014.01.016

[37] Gruman, J., Rovner, M.H., French, M.E., Jeffress, D., Sofaer, S., Shaller, D., et al. (2010) From Patient Education to Patient Engagement: Implications for the Field of Patient Education. Patient Education and Counseling, 78, 350-356. https://doi.org/10.1016/j.pec.2010.02.002

[38] Holzmueller, C.G. and Wu, A.W.P.P. (2012) A Framework for Encouraging Patient Engagement in Medical Decision Making. Journal of Patient Safety, 8, 161-164. http://www.ncbi.nlm.nih.gov/pubmed/22892584 https://doi.org/10.1097/PTS.0b013e318267c56e

[39] Knowlton, A.R., Arnsten, J.H., Eldred, L.J., Wilkinson, J.D., Shade, S.B., Bohnert, A.S., et al. (2010) Antiretroviral Use among Active Injection-Drug Users: The Role of Patient-Provider Engagement and Structural Factors. AIDS Patient Care and STDS, 24, 421-428. http://www.ncbi.nlm.nih.gov/pubmed/20578910 https://doi.org/10.1089/apc.2009.0240

[40] Kralik, D., Koch, T. and Wotton, K. (1997) Engagement and Detachment: Understanding Patients' Experiences with Nursing. Journal of Advanced Nursing, 26, 399 407. https://doi.org/10.1046/j.1365-2648.1997.1997026399.x

[41] Laschinger, S.H.K. and Leiter, M.P. (2006) The Impact of Nursing Work Environments on Patient Safety Outcomes: The Mediating Role of Burnout/Engagement. Journal of Nursing Administration, 36, 259-267. https://doi.org/10.1097/00005110-200605000-00019

[42] Lewis, N., Gray, S.W., Freres D.R. and Hornik, R.C. (2009) Examining Cross-Source Engagement with Cancer-Related Information and Its Impact on Doctor-Patient Relations. Health Communication, 24, 723-734.

http://www.pubmedcentral.nih.gov/articlerender.fcgi?artid=2950967\&tool=pmcent rez\&rendertype $=$ abstract https://doi.org/10.1080/10410230903264030

[43] Martinez, L.S., Schwartz, J.S., Freres, D., Fraze, T. and Hornik, R.C. (2009) Patient-Clinician Information Engagement Increases Treatment Decision Satisfaction 
among Cancer Patients through Feeling of Being Informed. Patient Education and Counseling, 77, 384-390.

http://www.pubmedcentral.nih.gov/articlerender.fcgi?artid=3279194\&tool=pmcent rez\&rendertype $=$ abstract https://doi.org/10.1016/j.pec.2009.09.008

[44] Pelletier, L.R. and Stichler, J.F. (2013) Action Brief: Patient Engagement and Activation: A Health Reform Imperative and Improvement Opportunity for Nursing. Nursing Outlook, 61, 52-54. https://doi.org/10.1016/j.outlook.2012.11.003

[45] Piette, J.D., Rosland, A., Marinec, N.S., Striplin, D., Bernstein, S.J. and Silveira, M.J. (2013) Engagement with Automated Patient Monitoring and Self-Management Support Calls. Medical Care, 51, 216-223. https://doi.org/10.1097/MLR.0b013e318277ebf8

[46] Protheroe, J., Rogers, A., Kennedy, A.P., Macdonald, W. and Lee, V. (2008) Promoting Patient Engagement with Self-Management Support Information: A Qualitative Meta-Synthesis of Processes Influencing Uptake. Implementation Science, 3, 44. https://doi.org/10.1186/1748-5908-3-44

[47] Pryor, J. and Buzio, A. (2010) Enhancing Inpatient Rehabilitation through the Engagement of Patients and Nurses. Journal of Advanced Nursing, 66, 978-987. http://www.ncbi.nlm.nih.gov/pubmed/20337804 https://doi.org/10.1111/j.1365-2648.2009.05237.x

[48] Ruusuvuori, J. (2001) Looking Means Listening: Coordinating Displays of Engagement in Doctor-Patient Interaction. Social Science \& Medicine, 52, 1093-1108.

[49] Schaefer, J.A., Ingudomnukul, E., Harris, A.H.S. and Cronkite, R.C. (2005) Continuity of Care Practices and Substance Use Disorder Patients' Engagement in Continuing Care. Medical Care, 43, 1234-1241. https://doi.org/10.1097/01.mlr.0000185736.45129.95

[50] Sheridan, N.F., Kenealy, T.W., Kidd, J.D., Schmidt-Busby, J.I.G., Hand, J.E., Raphael, D.L., et al. (2015) Patients' Engagement in Primary Care: Powerlessness and Compounding Jeopardy. A Qualitative Study. Health Expectations, 18, 32-43. https://doi.org/10.1111/hex.12006

[51] Shippee, N.D., Domecq Garces, J.P., Prutsky Lopez, G.J., Wang, Z., Elraiyah, T.A., Nabhan, M., et al. (2015) Patient and Service User Engagement in Research: A Systematic Review and Synthesized Framework. Health Expectations, 18, 1151-1166. https://doi.org/10.1111/hex.12090

[52] Staniszewska, S.H. and Henderson, L. (2005) Patients' Evaluations of the Quality of care: Influencing Factors and the Importance of Engagement. Journal of Advanced Nursing, 49, 530-537. http://www.ncbi.nlm.nih.gov/pubmed/15713185 https://doi.org/10.1111/j.1365-2648.2004.03326.x

[53] Thomson, R., Murtagh, M. and Khaw, F.-M. (2005) Tensions in Public Health Policy: Patient Engagement, Evidence-Based Public Health and Health Inequalities. Quality and Safety in Health Care, 14, 398-400.

http://www.scopus.com/inward/record.url?eid=2-s2.0-29244482259\&partnerID=tZ Otx3y1 https://doi.org/10.1136/qshc.2005.014175

[54] Young, D., Furler, J., Vale, M., Walker, C., Segal, L., Dunning, P., et al. (2007) Patient Engagement and Coaching for Health: The PEACH Study-A Cluster Randomised Controlled Trial Using the Telephone to Coach People with Type 2 Diabetes to Engage with Their GPs to Improve Diabetes Care: A Study Protocol. BMC Family Practice, 8, 20. https://doi.org/10.1186/1471-2296-8-20

[55] Boutin, M. (2012) Among Other Flaws, Hypothetical Migraine Study Lacks Inde- 
pendent Evaluation and Patient Engagement. Health Affairs, 31, 2231-2235. https://doi.org/10.1377/hlthaff.2012.0764

[56] Paladugu, R., Schein, M., Gardezi, S. and Wise, L. (2002) One Hundred Citation Classics in General Surgical Journals. World Journal of Surgery, 26, 1099-1105. https://doi.org/10.1007/s00268-002-6376-7

[57] Arora, N.K. and McHorney, C.A. (2000) Patient Preferences for Medical Decision Making: Who Really Wants to Participate? Medical Care, 38, 335-341. https://doi.org/10.1097/00005650-200003000-00010

Submit or recommend next manuscript to SCIRP and we will provide best service for you:

Accepting pre-submission inquiries through Email, Facebook, LinkedIn, Twitter, etc. A wide selection of journals (inclusive of 9 subjects, more than 200 journals) Providing 24-hour high-quality service User-friendly online submission system Fair and swift peer-review system Efficient typesetting and proofreading procedure Display of the result of downloads and visits, as well as the number of cited articles Maximum dissemination of your research work

Submit your manuscript at: http://papersubmission.scirp.org/ Or contact ojn@scirp.org 